\title{
THE MICRO-GEOGRAPHY OF TAX AVOIDANCE: EVIDENCE FROM LITTERED CIGARETTE PACKS IN CHICAGO \\ By David Merriman*
}

This paper describes a simple but novel technique for assessing cigarette tax compliance: inspection of littered cigarette packs to determine whether legally required taxes have been paid. In addition to serving as a measure of tax compliance, this approach is also a potential tool for assessing the impact of factors such as cigarette tax increases and tax disparities in adjacent areas on tax avoidance.

Between January 2002 and the summer of 2007 at least 36 states and the District of Columbia increased their cigarette tax rates (Goolsbee, Lovenheim and Slemrod 2007) in an effort to discourage smoking and raise revenue. Such tax increases may result in decreased consumption, but may also produce other behaviors such as use of lowerpriced cigarettes, hand-rolling cigarettes from loose tobacco, or smoking a smaller number of cigarettes more intensively.

Tax increases have sometimes created large tax disparities in neighboring communities. For example, in July of 2007 the City of Chicago had a combined state and

\footnotetext{
* Institute of Government and Public Affairs, Department of Public Administration and Department of Economics, University of Illinois Chicago, 815 W. Van Buren Street, Suite 525, Chicago, Illinois 60607-3506. dmerrim@uic.edu. Robert Wood Johnson Substance Abuse Policy Research Program (SAPRP) provided financial support. Gilbert Bassett, Fred Bryant, Christina Ciecierski, Micheal Lovenheim, Hana Ross, Joel Slemrod, John Tauras as well as two anonymous reviewers provided useful advice at various stages of the project. Many government officials also cooperated as explained in the text. Seminar participants at the University of Illinois and Northwestern University and National Tax Association annual meetings also provided helpful comments. Numerous assistants worked on the project and cheerfully and patiently engaged in a large variety of unorthodox tasks to collect and code the data reported here. Their names are Eishita Shah, William Barrett, Muhammed Zamar, Istvan Fekete, Lucia Samayoa, Amosh Noviandri, Maura Mahler, Jami Eddington, Robert Madeja, Vinca Merriman, Kyle Peyton, William Pokin, and Jeffrey Wytaniec.
} 
local tax of $\$ 3.66$ per pack, while neighboring Indiana had a state tax of only 55.5 cents per pack and no local cigarette excise taxes. The tiny state of Rhode Island had a tax of \$2.46 per pack while its neighboring states of Massachusetts and Connecticut had taxes of only \$1.51 per pack. Oklahoma’s tax of \$1.03 per pack was 86 cents higher than its border state, and Missouri and Montana’s tax of $\$ 1.70$ was $\$ 1.26$ higher than adjacent North Dakota.

Non-uniform taxes heighten the possibility of tax non-compliance (failure to pay the applicable tax in the location in which the pack was consumed) and avoidance (behavioral change designed to reduce tax liability). Economic theory predicts that tax avoidance will vary with the absolute level of taxes, tax disparities and the cost of avoidance, such as distance to lower tax sources. High taxes and tax disparities increase the incentive for organized smuggling, tax evasion at the point of sale, and cross border shopping in neighboring lower tax areas.

Cigarettes represent a useful laboratory for the study of tax avoidance behavior, given their relatively high taxes, easy access to low-tax or no-tax cigarette sources such as Native American reservations or the Internet, and a relative lack of enforcement efforts. The literature on tax compliance (see Andreoni, Erard and Feinstein, 1998, and Slemrod, 2007 for reviews) often has focused on avoidance or evasion of federal taxes. Slemrod (2007), for example, calculates an aggregate tax gap, defined as the federal income tax that is not collected on personal income, equal to about 14 percent of the revenue collected from federal personal income taxes. In contrast, there have been few studies of the effects of the cost of avoidance on behavior. The geography of cigarette 
taxes provides an exogenous source of variation in avoidance costs, allowing for a clean estimate of the relationship between tax avoidance and its cost.

The approach used in this paper leverages the fact that tax compliance measures can be visually identified on many cigarette packs. In all states except North and South Carolina, wholesalers must affix state tax stamps to cigarette packs before distributing them to retailers to indicate that taxes have been paid. When additional local taxes are imposed the state stamp is altered or an additional local tax stamp is added. As a result, the origin of purchases is observable on littered packs.

Working in the "unobtrusive measures" tradition of Eugene T. Webb et. al. (1966), the author organized teams to collect littered cigarette packs in a representative random sample of areas in the city of Chicago and neighboring jurisdictions. A separate survey of appropriately disposed cigarette packs from some of the same areas was also conducted. The tax stamps from the collected packs were examined to determine the extent of non-compliance.

In principle this data collection technique provides information about avoidance behavior such as organized smuggling, out-right evasion and cross-border shopping ${ }^{1}$. Of course, some non-compliance would be expected even if cigarette tax rates were uniform, since many people routinely cross tax borders in the normal course of their activities. Avoidance can be inferred from greater than random non-compliance levels. This is discussed in more detail later in the paper. This study revealed a high degree of noncompliance, with three quarters of Chicago packs not displaying the Chicago tax stamp, and compliance increasing with distance to low-tax borders. 
This paper examines recent literature on cigarette tax avoidance as well as the rationale for using littered cigarette packs as a possible measure for this behavior. It then describes the sampling, data collection, and data coding procedures employed in this study, followed by summary results and detailed regression data. Finally, it explores the evidence for littered packs as a measure of consumption as well as overall conclusions.

I. Brief review of the literature on cigarette tax avoidance and evasion Much of the literature has treated cigarette tax avoidance as a nuisance that makes it more difficult to get accurate estimates of the price elasticity of demand for smoking rather than a subject of direct interest. Usually cigarette tax avoidance has been measured indirectly by correlating residuals from cigarette demand equations with variables that are plausibly connected to smuggling or cross-border sales. These findings are often unsatisfying since it is difficult to definitively reject the hypothesis that some unobserved variable other than tax avoidance is responsible for the correlation with the residual.

Extensive reviews of the literature on the demand for cigarettes are contained in U.S. Department of Health and Human Services (HHS) (2000) and Frank Chaloupka and Kenneth E. Warner (2000). Authors in this literature generally do not highlight findings with respect to smuggling and tax avoidance because it is a secondary issue in these studies. Within the literature specifically on cigarette tax avoidance Andrew Hyland et. al. (2004), Mark Stehr (2005),Michael F. Lovenheim (2008), and Lesley Chiou and Erich Muehlegger (2008) are most closely related to the work described here². 
Hyland et. al. (2004) conducted telephone interviews with more than 900 randomly selected smokers in upstate New York counties that are close to Native American reservations. About two-thirds of respondents indicated that they purchased cigarettes from such reservations where state and local taxes may be evaded.

Stehr (2005) used regression analysis to compare cigarette consumption data from the Behavioral Risk Factor Surveillance System to tax paid cigarette sales, finding that reported consumption is only 57 percent of reported sales yet does not drop as much as sales when taxes increase. After carefully controlled statistical analyses, he concluded that tax avoidance accounted for up to 9.6 percent of sales but that a miniscule share of this (less than one percent) was due to cross-border shopping between 1985 and 2001.

Lovenheim (2008) used data aggregated at the metropolitan area level to regress cigarette consumption as reported in several waves of the Current Population Survey (CPS) against price and the distance of an average consumer to a lower-priced border. Lovenheim includes other control variables and infers inter-metropolitan differences in tax avoidance from the observed correlation between reported consumption and a variable that interacts average distance to lower priced cigarettes with cross-state price differences. He estimates average cigarette tax avoidance rates between 13 and 25 percent. Chiou and Muehlegger (2008) conclude that the average individual who lives near a lower-priced jurisdiction is willing to travel three miles to save one dollar on a pack of cigarettes, and that existing cigarette taxes tend to fall below tax-revenue maximizing levels, using data from the CPS Tobacco Use Supplement.

The contribution of the work reported here is to provide observable rather than inferential evidence of cross-border shopping, and to document the relationship between 
compliance and intra-metropolitan differences in distance to lower priced sources of cigarettes. While a few researchers have used discarded cigarette packs to learn about tax compliance (Lakhdar (2008) and unpublished studies from the United Kingdom Tobacco Manufacturers Association (UKTMA)) this is the first to use a systematic data collection strategy designed to measure how compliance varies with location and level of tax ${ }^{3}$. The research strategy used here makes it possible to explicitly estimate a gradient that relates distance to the probability of compliance.

\section{Overview of study approach}

This study collected direct evidence of tax avoidance from littered cigarette packs in a well-documented, systematic and representative manner. It collected this data from numerous regions within the city of Chicago and adjacent municipalities, including ones in the lower-tax state of Indiana, to compare patterns of purchase origin using tax stamps. This data was compared to legitimately disposed cigarette packs and point-of-purchase data from selected locations.

A major advantage of this approach is that the location of purchase is unambiguously identified by the required tax, and the location of consumption can be inferred with little ambiguity by the location at which the pack is found. Unlike conventional approaches that use data from observed sales or surveys, studies using littered packs eliminate the need to (1) estimate unknown functional forms for demand functions (2) use a small and relatively arbitrary set of variables to control for the ease of tax avoidance (3) aggregate data across space (e.g. several states) and/or over time when various factors other than changes in cigarette taxes might influence consumption and tax 
avoidance, and (4) correct for under-reporting in self-reports of smoking behavior, which is believed to be large.

Littered packs are likely to be dropped with no thought as to the legality of the cigarette pack because it is impossible to trace the pack to its owner. One concern about this source of data, however, is that litterers may be systematically different than nonlitters with regard to tax avoidance behavior. However, limited evidence suggests that littering is not confined to any particular socio-demographic group; for example, Australian research teams observing the disposal of rubbish in public places such as parks and outdoor shopping malls found that 23 percent littered littered across all ages and backgrounds, with little correlation with gender or access to bins. (Williams, Curnow, Streker 1997 p.7). Some additional direct evidence about bias in the litter sample below is provided below, but even if this objection cannot be entirely dismissed, studies of litter can be informative about how tax avoidance varies across space ${ }^{4}$.

Chicago provides an almost ideal location in which to use littered cigarette packs to study tax avoidance, with many tax borders in close proximity. Figure 1 is a map of total state and local excise taxes on cigarettes in the Chicago area at the time of data collection during the summer of 2007. The map shows all of Cook County, portions of the Illinois counties of Lake, DuPage and Will, the portion of Indiana that borders on Cook County, and borders of several municipalities located within Cook County and next to the city of Chicago.

\section{[insert Figure 1 Map of Total (Federal+State+Local) about here]}

Cigarette excise taxes may be levied by federal, state, county and city governments. At the time of the data collection in the summer of 2007 , federal taxes were $\$ 0.39$ per pack, while state taxes were 98 cents per pack in Illinois and 55.5 cents per pack in Indiana. 
There were no sub-state taxes in Indiana. Cook County had a \$2 per pack cigarette tax but other Illinois counties had no tax. Within Cook County, the municipalities of Berwyn, Cicero, Chicago, Evanston, and Rosemont levied additional taxes. The city of Chicago had the highest city tax at $\$ 0.68$ per pack, followed by Evanston ( $\$ 0.50$ per pack), Berwyn and Cicero (\$0.16 per pack) and Rosemont (\$0.05 per pack). No other cities in Cook County or any of the other counties in Illinois levied cigarette taxes. These represent large differences across a relatively small geographic area, with total taxes varying from $\$ 4.05$ per pack in Chicago to 1.37 in DuPage, Lake and Will counties in Illinois and $\$ 0.945$ in Indiana ${ }^{5}$ For a pack a day smoker, purchasing cigarettes in Indiana rather than Chicago would result in savings of more than $\$ 1,100$ per year ${ }^{6}$.

Wholesalers that provide cigarettes to retail outlets in Chicago must affix an Illinois state stamp and a joint city-county stamp to each pack, including those offered for sale in cartons. The joint city-county stamp provides evidence that the Cook County and Chicago taxes have been paid. Figure 2 shows examples of Chicago, Cook County, Illinois and Indiana tax stamps. Although there is no federal requirement for the use of tax stamps governments typically employ them to monitor compliance. The stamps generally contain distinctive colors and shapes that help to identify them even when some lettering on the stamp cannot be read. There is no stamp showing that the federal tax has been paid ${ }^{7}$.

\section{[Include figure 2 about here]}

\section{Data collection methods}

The data collection strategy used in this study was designed to produce a representative sample of cigarette packs smoked within the city of Chicago. Littered 
cigarette packs were collected within specific geographic regions within and adjacent to the city to obtain a statistically valid estimate of tax avoidance in the city of Chicago and its border region.

For transportation planning and other purposes the city is divided into 930 transportation analysis zones (TAZs) defined by the federally designated metropolitan transportation planning agency. In the Chicago region TAZs closely follow the traditional township boundaries first established by the Land Ordinance of 1785 and usually are a one-half-mile by one-half-mile rectangle ${ }^{8}$. Census data were matched to each TAZ using geographical information systems to overlay census tract maps on TAZ maps. Population and employment in the TAZ were estimated assuming that they were equally distributed within TAZs and census tracts.

Data was collected from 100 TAZs that were in the city of Chicago., The TAZs were selected using a weighted random sample so that TAZs with higher populations (100\% weight) and employment (49\% weight) were more likely to be selected ${ }^{9}$. If the average person smokes and litters two-thirds of their cigarettes at home and one-third at work the weights assure all littered packs are equally likely to be included in the sample. This study also drew a weighted random sample of 30 of the 160 Cook County TAZs that border on, but are outside, the legal boundaries of the city of Chicago for comparison purposes. By chance, these did not include TAZs in Rosemont, Cicero. Berwyn does not border on Chicago. Two of the sampled border TAZ are in Evanston but these TAZs are not meant to be representative of Evanston and the littered packs in these TAZs contained no Evanston stamps. Since the data provides little evidence about compliance with city taxes in Evanston, Rosemont, Berwyn and Cicero I ignore these taxes in the remainder of the paper. 
Data also were collected from all five TAZs that border Chicago from outside Cook County, three of which are in DuPage County and two of which are in Indiana. A summary of the universe and sample is given in Table 1.

\section{[insert Table 1 about here]}

A street map was overlaid on a satellite photo for each of the 135 sample TAZs and a one mile data collection route was designated. Routes were selected to assure that they provided safe places to walk as well as appropriate places to find littered packs. A typical route required collectors to walk one-half mile on the north side of the street along a commercial strip, at which point they crossed to the south side of the street and walked one-half mile back to the starting point.

Teams of data collectors consisting of at least two people walked precisely along each designated route. Since tax stamps are affixed to the cellophane, only packs with cellophane could be used to determine if taxes were paid. To simplify data collection and avoid arbitrary judgments in the field, collectors were told to pick up every littered pack on the route. Data was collected from each TAZ on a single occasion between mid-May and mid-June $2007^{10}$.

Collected packs were returned to the research office and labeled with a unique serial number indicating the TAZ where it was found. Teams of research assistants were trained to identify tax stamps from Illinois, Cook County, Chicago, Indiana, and Wisconsin. Research assistants completed a computerized questionnaire about the serial number, brand, and, most important the tax stamps on each pack. The packs were coded twice and a computer program was used to identify cases in which the first coding of tax 
stamps did not match the second coding. Research assistants located all packs where discrepancies were found and determined the correct coding.

IV. Basic results

This section summarizes the results of the collection and analysis of littered cigarette packs within the regions outlined in the previous section. The data provide evidence of a substantial degree of tax avoidance in Chicago, and to a lesser extent in the surrounding suburbs, results that are consistent with the predictions of economic theory.

Data collectors found a total 2,391 littered cigarette packs, 1,141 (47.7 percent) of which had cellophane attached so that tax stamps could be identified if present. Figure 3 provides information about where packs were found.

\section{[insert figure 3 Map of Sample TAZs about here]}

These raw data were used to construct estimates of the prevalence of tax compliance in each of four groups of TAZs defined by city, county and state boundaries as enumerated in Table 1. These estimates assume each littered pack is a random draw from an identically distributed and independent binomial distribution with a probability of compliance that is constant within a TAZ, but that varies across TAZs. The total observed number of packs that comply with a given tax within a TAZ thus has a Bernoulli distribution. Because this study drew a weighted random sample of TAZs in each group the un-weighted average of the observed TAZ-specific probabilities is an unbiased estimate of the true group-wide probability of compliance (see Merriman 2008).

\section{[insert Table 2 about here]}

As shown in Table 2, 59 percent of packs found in Chicago had Illinois stamps and 29 percent had Indiana stamps. Five percent have stamps from another state and 
seven percent have no state tax stamp, which could indicate that they were purchased from remote locations via the Internet or from Native American reservations. Only onequarter (25 percent) of littered packs in Chicago had a Chicago tax stamp while slightly more than one-third (36 percent) contained evidence that the $\$ 2$ per pack Cook County tax had been paid; in fact, in Chicago littered packs were slightly more likely to have an Indiana stamp than a Chicago stamp.

Some non-compliance is to be expected in a metropolitan area where people routinely travel between tax zones, i.e. geographic areas with a single tax rate. One simple upper bound estimate of expected incidental non-compliance in Chicago is the share of Chicago stamps found in non-Chicago Cook County TAZs. This is an upper bound because all of the non-Chicago Cook county TAZs border on Chicago while only a small fraction of the Chicago TAZs border on Cook County. The share of Cook County stamps found in Chicago (36 percent) is more than twice as great as the share of Chicago stamps found in Cook County (15 percent). Comparisons of Indiana stamps in Chicago with Chicago stamps in Indiana and Chicago stamps in DuPage with Illinois (only) stamps in Chicago yield even stronger evidence of tax avoidance, assuming symmetric inter-area commuting flows. Despite small samples from DuPage County and from Indiana, avoidance of state taxes appears to be much smaller in these locations. In the three DuPage County TAZs that border Chicago 83 percent of littered packs were estimated to have an Illinois stamp, however 19 percent of the packs in these DuPage county TAZs had a Cook county stamp and ten percent had a Chicago stamp. This may be explained by the fact that many Chicago residents routinely travel to and from these border TAZs for work, shopping, or 
other purposes and may litter packs they have purchased elsewhere. In the two Indiana TAZs that border Chicago, 97 percent of the packs have an Indiana stamp.

The random sample of 30 TAZs that are in Cook County and border Chicago was designed to be representative of all 160 such TAZs. Within this sample it was estimated that more than three-quarters (76 percent) of the packs in border TAZs have an Illinois tax stamp and 51 percent have paid Cook County taxes.

Geographic patterns of compliance provide some evidence that the more effort is required to avoid the tax, the less people will do it. Figure 4 contains three maps showing the share of packs with Illinois, Cook County and Chicago stamps. Data was suppressed in TAZs where less than five packs were found because the high variance of the results in those TAZs may be misleading. Figure 4A shows that many fewer Illinois stamps were found in TAZs near the Indiana border. Figures 4B and 4C show that while Chicago and Cook County stamps were relatively rare everywhere, they were most plentiful in downtown and on the northeast side of the city, two regions relatively far from low-tax jurisdictions. These maps are consistent with the hypotheses that non-compliance with the Illinois tax is most prevalent close to Indiana and non-compliance with the Chicago and Cook County taxes is most common close to state, county and city borders.

\section{[insert Figure 4 about here]}

Spatial patterns of non-compliance contain valuable information about tax avoidance. Even if no one crossed borders to avoid taxes, it is likely that some littered cigarette packs in Chicago would have non-Chicago tax stamps simply because people routinely commute for employment and other purposes. Three groups of people litter cigarette packs: workers, resident non-workers, and visitors such as shoppers or tourists. 
Census “journey to work” data on commuting was used to obtain an approximate quantitative estimate of the share of "foreign stamps" in Chicago litter to be expected if cigarette prices did not vary geographically.

In the absence of purposeful tax avoidance the share of foreign stamps expected in the litter dropped by those working in a particular area would be a weighted average of the cigarettes bought by workers at their resident and work TAZs ${ }^{11}$. Since an eight hour workday implies that commuters spend one-third of their time in their work TAZ in a typical day this study assumed that, in the absence of purposeful tax avoidance, one-third of cigarettes would be purchased and consumed in the work TAZ and one-third would be purchased and consumed in the residence TAZ. Combining this assumption with Census data leads to prediction that about 85 percent of the littered packs dropped in Chicago should have a Chicago stamp, 94 percent should have a Cook county stamp and 99 percent should have an Illinois stamp. The results vary little even with assumptions that a considerably higher or lower share of cigarettes are bought and consumed in the work TAZ. For example, if 50 percent are purchased and consumed in the work TAZ, 83 percent of Chicago's litter would have non-Chicago stamps. if ten percent of cigarettes are purchased and consumed in the work TAZ 94 percent of Chicago's litter would have Chicago stamps.

TAZ specific data on commuting flows was used to obtain naïve predictionsassuming no purposeful non-compliance—of compliance by TAZ. TAZs were then arrayed by distance to the Indiana border. Figures 5A and 5B show bar graphs of observed compliance and naïve predictions of compliance with Chicago and Cook County taxes arrayed by distance to the Indiana border. In figure 5A the naïve model 
predicts that at least 81 percent of littered packs will have a Chicago stamp and there is little relationship between distance to the Indiana border and predicted share of Chicago stamps. In the observed data the share of packs with a Chicago stamp increases with distance to the Indiana border and rises to a maximum of only one-third. As shown in Figure 5B the observed share of Cook County stamps in Chicago border TAZ is far less than the share predicted by the naïve model and, with a few exceptions, rises with distance to the Indiana border.

\section{[insert figure 5 about here]}

The simple tests embodied in figures 5A and 5B yield results that are broadly consistent with the predictions of economic theory, i.e. compliance is lower where taxes are higher and rises with the cost of compliance (measured by distance to the Indiana border).

Non-Chicago cigarette stamps also might be brought into the city by resident nonworkers, who represent almost 43 percent of Chicago residents over the age of 18, as well as tourists and other visitors. It seems likely that resident non-workers would have less reason to travel outside of city boundaries then workers and thus, in the absence of purposeful tax avoidance, would result in reduced estimates of non-compliant stamps.

Tourists and other visitors might be more likely to litter packs with non-compliant stamps but they account for a small fraction of person nights in Chicago. In any case, it is unlikely that packs littered by tourists and other visitors have an important influence on the results reported here. In Chicago, most visitors spend the majority of their time in the downtown area housing corporate and tourism destinations, however basic results about 
tax compliance (reported in Table 2) are nearly identical when data collected in the central area of Chicago is omitted.

\section{Regression results}

A more formal test of the hypothesis that proximity to lower tax sources of cigarettes decreases the probability of compliance is shown in Table 3, reporting marginal effects from a probit regression on the probability that a littered pack has a local tax stamp-i.e. the tax stamp that would be found on a legally purchased pack in the TAZ where the littered pack was found. Economic logic suggests that compliance should increase with distance to a lower tax border and the relative amount of local residents/workers, and compliance should decrease with the the tax in the TAZ.

\section{[insert table 3 about here]}

The regression results in model 1 of table 3 control for only these three factors. Although the hypothesis that the marginal effect of distance to a lower tax border is zero cannot be rejected, the results on all three categories of independent variables are consistent with economic theory. The amount of local residents/workers is measured by the weighted share of TAZ residents who live and work in the TAZ's tax zone, i.e. a geographic area with a single tax rate ${ }^{12}$. In model 1 the insignificant point estimate on this coefficient on this variable implies that a one point increase in the share of local residents/workers raises the probability of a local stamp by 0.37 percent. The TAZs in this data set are located in only three tax zones, Chicago, non-Chicago Cook County, and Illinois outside Cook County. Thus dummy variables controlling for whether the TAZ is in Chicago or non-Chicago Cook County completely control for tax differences. The estimated coefficient on the dummy variable for a Chicago TAZ is significant and 
implies that the $\$ 2.68$ difference between the cigarette tax in the city of Chicago and the cigarette tax in non-Cook Illinois decreases the probability of finding a local stamp by more than 60 percent. With the small sample of TAZs outside of Cook County, it may not be surprising that the coefficient on the Cook TAZ dummy is insignificant. The point estimate suggests that the $\$ 2$ difference between taxes in Cook County and in non-Cook County Illinois decreases the probability of finding a local stamp by about 35 percent.

The regression results in model 2 of table 3 add controls for a number of land use, economic and demographic variables. The probability of finding a local tax stamp is higher in TAZs in which more land is used for commercial purposes, probably because cigarettes can be bought right in the TAZ. As household income rises the probability of a local stamp also rises, perhaps because high income households are less likely to dedicate extra time and effort to circumventing cigarette taxes. However, the results suggest also that the probability of finding a local tax stamp increases with the share of households in poverty. This might be because households in poverty are less mobile than higher income households and find it difficult to travel to other tax zones and avoid the tax.

Finally, the higher the share of non-white households the lower the probability of finding a local stamp, perhaps because neighborhoods with high proportions of minorities are more likely to have formal or informal networks that allow circumvention of the cigarette taxes. The marginal effects of the relative share of local residents/workers and place dummies are all larger in model 2 than in model 1 and the dummy variable for location in non-Chicago Cook County is significant as is the coefficient on local residents/workers. 
Model 3 modifies model 2 by replacing distance to a lower tax border with distance to the Indiana border. When this is done the place dummies become insignificant but the share of land for single family housing becomes significant. All other marginal effects retain their sign and statistical significance. The marginal effect of distance to the Indiana border suggests that moving a TAZ one mile further from Indiana increases the probability of a local stamp by approximately one percent.

Table 4 supplements the results shown in Table 3 by investigating factors that influence the probability of finding a specific tax stamp in TAZs located in Chicago and non-Chicago Cook while taking account of the distance to multiple tax borders. These regressions include variables that measure the distance to the Chicago border, the additional distance (if any) from the Chicago to the Cook County border, and the additional distance (if any) from the county to the state border. Each of these three distances may be important as smokers decide whether to circumvent cigarette taxes by traveling to lower tax areas. For some smokers, specifically those on the far southeast side, the distance to the Chicago border is equal to the distance to the county and state borders. These smokers can reduce taxes by $\$ 3.11$ per pack by crossing the city border. Other smokers such as those who live on the far northwest side save only the 68 cent Chicago tax by crossing the city border since doing this does not avoid county or state taxes. We clearly expect more avoidance of the Chicago city tax at a given distance from the Chicago border among the first group of smokers then among the second, therefore controlling for the ease of avoidance requires multiple measures of distance.

[insert table 4 about here] 
These regressions also include measures of the share of Illinois, Cook County and (in models 1 through 3) Chicago residents/workers. The probability of avoidance also depends on the tax difference between areas, However within an area there is no variance in the savings resulting from crossing a given tax border, making it difficult to identify the coefficient on this variable in these regressions.

Model 1 of table 4 shows the marginal effects obtained from a probit regression on the probability of finding an Indiana stamp in a TAZ located in Chicago. This probability decreases as distance to the Chicago, Cook County and Indiana borders increases. According to the regression results, holding constant distance from the county to the state border and distance from the city to the county border, a one mile increase in distance to the city border decreases the probability of finding an Indiana stamp by approximately 5 percent. Similarly, holding constant distance from the county to the state border and distance from the TAZ to the city border, a one mile increase in distance to the county border decreases the probability of finding an Indiana stamp by almost three percent. Finally, holding constant distance from the TAZ to the city and county borders, a one mile increase in distance to the Indiana border decreases the probability of finding an Indiana stamp by about 2.6 percent. The marginal effect of the share of Chicago, nonChicago Cook County, and Illinois workers/residents are all insignificant, suggesting that routine commuting behavior does not help explain the variation in non-compliance among Chicago TAZs. The marginal effects of changes in the land use and economic variables are reversed compared with the results shown in table 3 because an Indiana stamp would be a non-local stamp if found in a Chicago TAZ.

Models 2 and 3 of Table 4 repeat the exercise using Cook county stamps and Chicago stamps as the dependent variable. In model 2 none of the distance or share of 
local worker/residents variables are significant and explanatory power is considerably reduced. In model 3 the probability of finding a Chicago stamp significantly increases with distance to the Indiana border, holding constant distance to the city and county borders, but none of the other distance or share of local worker/residents variables have a significant impact and the regression has little explanatory power.

Models 4 and 5 of table 4 report the marginal effects from similar regressions using the packs found in 30 non-Chicago Cook County TAZs. The probability of finding an Indiana stamp (model 4) in these TAZs is not significantly correlated with distance to the county or Indiana border but rises significantly as the share of non-Cook County Illinois worker/residents increases. Thus, as would be expected, Indiana stamps are less common in TAZs where there are more within-county commuters and more common in TAZs where there are more cross-county commuters. The probability of finding a Cook county stamp in these TAZs increases significantly with distance to the Indiana border and with the share of non-Chicago Cook worker/residents, suggesting that compliance is affected by both routine commuting patterns and distance to tax borders.

Coefficients from the regressions reported in columns 1, 2, and 3 of Table 4 are used to plot the predicted probability of finding each type of tax stamp, conditional on observed distances to the Chicago and Cook County border and mean value of other independent variables, against distance to the Indiana border as displayed in figure 6 .

\section{[insert figure 6 about here]}

Very close to Indiana-Chicago border about 80 percent of packs contain an Indiana tax stamp, however this declines quickly with distance, and 30 miles from that border (roughly the distance from the Indiana border to Rosemont’s southeastern border 
in figure 1) almost no packs have Indiana stamps. The probability of Chicago and Cook County stamps grows with distance to the Indiana border. The probability of finding a Chicago stamp reaches a maximum of approximately 37 percent 30 miles from the border, while the probability of a Cook County stamp is about 45 percent at that distance.

An analogous plot was generated using the coefficients from models 4 and 5 of Table 4 as displayed in figure 7. In Cook County TAZs bordering on Chicago compliance is correlated with distance to the Indiana border. Close to the Indiana border the probability of an Indiana stamp is about 22 percent, however this probability falls as distance to the border increases, and the probability of finding an Indiana stamp 30 miles from the border is about five percent. There also is a strong relationship between the predicted probability of a Cook County stamp and distance to the Indiana border. For TAZs within five miles of the Indiana border the predicted probability of a Cook County stamp is just 17 percent, however for TAZs located approximately 35 miles from the border the predicted probability rises to roughly 57 percent.

\section{[Insert figure 7 about here]}

\section{Representativeness of littered packs}

A prominent threat to the internal validity of this study was the potential nonrepresentativeness of a sample based on littered cigarette packs ${ }^{13}$. This study compared this littered cigarette pack data to samples of legitimately disposed cigarettes in specific areas, as well as purchase data from sales channels. While this latter data showed evidence of variations in brand distribution, the basic hypothesis that littered cigarette packs are representative of total consumption remains. 
Evidence discussed above shows that littering is a very widespread behavior engaged in by people of all socio-economic classes. Still, smokers who litter are necessarily those who have flaunted at least a minor law, and it is reasonable to ask whether they also might be unusually likely to circumvent tax laws.

This study compared tax compliance in littered and appropriately disposed of cigarette packs in a few areas. With the cooperation of the Chicago Department of Streets and Sanitation-the author was given access to public trash receptacles in three areas of the city. In these areas receptacles are emptied daily during summer months. One occasion involved riding with Streets and Sanitation and taking the trash from each receptacle in a large plastic bag. The plastic bags were brought to a suitable area and sorted to extract every cigarette pack found. The extracted packs were labeled based on where they were found and information about them was coded into a data base. In total trash from 40 receptacles was examined and one or more packs were found in 31 receptacles, including a total of 82 packs with cellophane.

In each of the areas research teams walked exactly the same streets within 24 hours looking for littered packs. In two of the areas no littered packs were found. In all three areas the receptacle sample was compared to the sample of litter obtained from the closest TAZ. Table 5 provides information from the three areas.

\section{[Insert Table 5 about here]}

In the first area data was obtained from three sources: a TAZ (\#414513) that was surveyed as part of the representative sample, trash receptacles, and littered packs collected on the same day along the same street that data was gathered from the trash receptacles. In this area 18 packs with cellophane were found in the trash receptacles 
(sample 2). Six of the packs had Chicago tax stamps and 12 did not. In the parallel search for litter (sample 3) nine cigarette packs, six of which did not have a Chicago tax stamp, were found.

In the nearest TAZ (sample 1) seven packs were found with cellophane, four or which had a Chicago tax stamp. In row 4 of the table the first number in square brackets gives the probability, conditional on the sample, that there is less compliance with Chicago taxes among littered packs than among appropriately disposed of packs in the area. This row presents the probability that there is less compliance with Illinois taxes, while the rest of the table presents data and tests analogous hypotheses for two other areas.

While the number of areas sampled is small, the data in Table 5 provides little evidence that smokers who litter disproportionately avoid applicable taxes. In two of the three cases there is higher compliance with both Illinois and Chicago taxes among littered cigarette packs than among nearby receptacles. In the third case, compliance with Illinois taxes is nearly equal among the two samples but there is higher compliance with Chicago taxes in the receptacle sample.

Another way to check the representativeness of the littered sample is to compare the distribution of cigarette brands in the Chicago tax paid litter sample with the distribution of cigarette brands reported by legal Chicago vendors. Table 6 compares the brand distribution in data collected from scanners in Chicago in the second quarter of 2002 to the weighted sample of tax paid littered packs found during the summer of 2007.

\section{[Insert Table 6 about here]}

In both distributions Marlboro is by far the leading brand and Camel, Kool and Parliament have small shares. The greatest differences between the two distributions are 
that the littered sample contains a much higher share of Newports (29\% versus $12 \%)$ and a much lower share of “Other” brands (9\% versus 25\%). One possible explanation for this discrepancy is that Newport gained market share during the period 2002 to 2007 at the expense of brands in the "Other" category. Another possibility is that because stores that use scanners tend to be large, they stock a greater variety of brands than the average. In this case, the scanner data might over-represent relatively obscure brands (collected in the "Other" category). Of course, it is also possible that the littered sample overrepresents Newports and under-represents “Other” brands ${ }^{14}$.

\section{Conclusions}

Taxes on cigarettes are intended to discourage use and raise revenue but tax avoidance may mute the impact of taxes. This study was designed to explore physical evidence of such tax avoidance by collecting littered cigarette packs from a sample of areas in and near the city of Chicago. The strength of the techniques described here is that they provide relatively precise, direct and easily understandable measures of tax compliance. These results provide strong and concrete evidence that a very large segment of the population avoids Chicago's very high cigarette tax. The empirical results are broadly consistent with economic theory and provide evidence that compliance rises as the costs of avoidance rises and tax differentials decrease.

While this source of direct evidence is potentially very informative it is important to investigate the possibility of selection bias. This investigation has provided some reassuring checks using evidence from receptacles and comparisons of brand distribution; it is still possible that litter provides bias estimates. Litterers may be disproportionately "scofflaws" and those who consume cigarettes in their homes (and thus do not litter) may 
be disproportionately likely to comply. Creative methods for investigating these hypotheses may be worthwhile topics of future research.

These empirical results show very low levels of tax compliance consistent with the survey findings of Hyland et al. (2004). While the results reported here are not directly comparable to econometric studies that report tax compliance only at the national or state level they are consistent with recent studies showing high level of avoidance ${ }^{15}$. The low level of tax compliance suggests that Chicago's cigarette tax base has eroded due to substantial tax avoidance. This does not necessarily imply that high cigarette taxes are failing to reduce consumption. Tax compliance increases rapidly with proximity to low-tax borders so that distance to lower-taxed alternatives provides a significant barrier to avoidance.

Previous research on this topic has generally inferred tax avoidance based on econometric analysis. By comparison, the simple, empirical approach outlined in this paper represents a means of quantifying tax avoidance, as well as the impact of both absolute and differential tax levels on such avoidance patterns. This research, in turn, provides a window on the relationship between cigarette taxation and smoking behavior within a realistic community-level context. 


\section{References}

Andreoni, James, Brian Erard and Jonathan Feinstein 1988. “Tax Compliance” Journal of Economic Literature 36(2): 818-860.

Chaloupka, Frank and Kenneth E. Warner 2000. "The Economics of Smoking," in The Handbook of Health Economics, ed. Joseph P. Newhouse and Anthony J. Cuyler, pages 1539-1627 New York: North-Holland, Elsevier Science B.V.

Chiou, Lesley and Erich Muehlegger 2008 "Crossing the Line: Direct Estimation of Cross-Border Cigarette Sales and the Effect on Tax Revenue,” The B.E. Journal of Economic Analysis \& Policy: Vol. 8: Iss. 1 (Contributions), Article 48. Available at: http://www.bepress.com/bejeap/vol8/iss1/art48

Goolsbee, Austan; Michael F. Lovenheim and Joel Slemrod Forthcoming. "Playing with Fire: Cigarettes, Taxes and Competition from the Internet” American Economic Journal: Economic Policy.

HM Treasury, HM Customs and Exercise March 2000. Tackling Tobacco Smuggling London, England. available at http://www.hmce.gov.uk

Hyland, Andrew Cheryl Higbee, Joseph E. Bauer, Gary A. Giovino, and K. Michael Cummings 2004. “Cigarette Purchasing Behaviors When Prices Are High” J Public Health Management Practice, 2004,10(6), 497-500

Lakhdar, C. Ben. 2008. "Quantitative and qualitative estimates of cross-border tobacco shopping and tobacco smuggling in France,” Tobacco Control 17:12-16.

Lovenheim, Michael F. 2008. "How far to the border?: The extent and impact of crossborder casual cigarette smuggling.” National Tax Journal 61(1):7-33.

Merriman, David, Ayda Yurekli and Frank Chaloupka. 2000 "How Big is the Worldwide Smuggling Problem?” in Tobacco Control Policies in Developing Countries eds. Prabhat Jha and Frank J. Chaloupka chapter 15 (p.365-392) . New York: Oxford University Press.

Merriman, David 2008. "Cigarette Tax Avoidance in the Chicago Area: A Contribution to the Litterature” http://www.igpa.uillinois.edu/library/WP-Merriman-CigLitter.

Slemrod, Joel 2007. “Cheating Ourselves: The Economics of Tax Evasion” Journal of Economic Perspectives 21(1): 25-48.

Stehr, Mark. 2005. “Cigarette Tax Avoidance and Evasion,” Journal of Health Economics 24 (2), March. 277-297. 
U.S. Department of Health and Human Services. Reducing Tobacco Use: A Report of the Surgeon General. Atlanta, Georgia: U.S. Department of Health and Human Services, Centers for Disease Control and Prevention, National Center for Chronic Disease Prevention and Health Promotion, Office on Smoking and Health, 2000.

\title{
Williams, Emma, Rob Curnow and Peter Streker 1997. Understanding Littering Behaviour in Australia. Mt. Martha, Victoria, Australia: Beverage Industry Environmental Council.
}

\author{
Webb, Eugene T., Donald T. Campbell, Richard D. Schwartz, Lee Sechrest 1966. \\ Unobtrusive Measures. Chicago: Rand McNally
}

\footnotetext{
${ }^{1}$ Counterfeiting of tax stamps is another potential source of non-compliance. The level of counterfeit stamps in this sample is extremely small. See Merriman 2008 for details.

${ }^{2}$ See Chiou and Muehlegger (2008) for a recent broader review of the literature.

${ }^{3}$ Information about UK TMA research was supplied (with permission) in a private communication from Judith Kelly of the UK Excise Office. UKTMA has collected a non-representative sample of littered cigarette packs on various occasions outside the matches of the Liverpool football club from 2000 to 2006 and near the Newcastle horse race course in 2005 and 2006. They consistently found that 25 to 40 percent of packs avoided UK taxes

${ }^{4}$ Several readers of this manuscript have suggested that simply asking people in the street to look at their cigarette packs might be an alternative to collecting littered cigarette packs. While this approach may have promise there are a large number of practical obstacles to its implementation.- -most importantly that the time required to collect a similar-sized sample would be much larger and the personal interactions more potentially biased then using a sample of litter (seem Merriman 2008 for more detail).

${ }^{5}$ These cigarette excise tax differences understate the total difference in taxes on a pack of cigarettes because the city of Chicago had a sales tax of nine percent which applied to the excise tax-inclusive price of cigarettes while Indiana's sales tax was six percent. Other areas in Illinois have a sales tax rate between 6.5 and nine percent.

${ }^{6}$ On July 1, 2007 Indiana raised its state tax to 99.5 cents. This changed occurred after the data employed in this study were collected.

${ }^{7}$ In summer 2007 average monthly sales of Chicago cigarette tax stamps were about five million, down from about ten million in 2001. The decline in stamp sales over this period closely tracks a series of five state and local cigarette tax increases that resulted in a cumulative increase of $\$ 2.68$ per pack.

${ }^{8}$ See the US Department of Transportation for more information about TAZs (http://www.fhwa.dot.gov/ctpp/taz/index.htm).

${ }^{9}$ The sample was designed to disproportionately contain high population and high employment TAZ where it would be easier to find littered packs. Data is weighted when doing analyses to reflect population parameters. I used a computer algorithm that selected the TAZs such that: $\frac{\operatorname{Pr}\left(S_{i}=1\right)}{\operatorname{Pr}\left(S_{j}=1\right)}=\frac{\left(\text { pop }_{i}+.49 e m p_{i}\right)}{\left(\text { pop }_{j}+.49 e m p_{j}\right)}$ and $\sum_{i=1}^{N} S_{i}=K$ where $\mathrm{S}_{\mathrm{i}}=1$ if $\mathrm{TAZ}_{\mathrm{i}}$ is in the sample and zero
} otherwise. pop $\mathrm{p}_{\mathrm{i}}$ and emp $\mathrm{p}_{\mathrm{i}}$ are the population and employment in $\mathrm{TAZ}_{\mathrm{i}}$ respectively and $\mathrm{K}$ is a constant (100 in the city of Chicago and 30 for TAZs that border Chicago in Cook county).

One TAZ, located very near O'Hare airport, is within the city of Chicago but in DuPage County and was selected in the random sample, because the need for payment of Cook County taxes in this small area is ambiguous it was dropped from most of the calculations in this paper. Also, the weighting scheme was influenced by technical constraints. Because employment is much more concentrated than population the highest weight that can be assigned to employment when selecting a population and employment weighted random sample of 100 TAZs from the universe of 930 Chicago TAZs without replacement is 49 percent. 
${ }^{10}$ Some TAZs were resampled in later periods. This data collection verified that results were consistent over time. Due to space constraints these results are not discussed here but see Merriman 2008 for discussion.

${ }^{11}$ Consider an area in which all residents are workers and there are just two jurisdictions labeled " $\mathrm{A}$ " and "B". The ratio of "foreign" littered packs to total littered packs in area A is:

(1) $\frac{L_{A}^{B}}{L_{A}^{A}+L_{A}^{B}}=\frac{\lambda_{A B} C_{R} p_{W}+\lambda_{B A} c_{W} p_{R}}{\lambda_{A B} C_{R}+\lambda_{A A}+\lambda_{B A} c_{W}}$ where $L_{A}^{i}$ is the number of packs with stamps from area i $(=\mathrm{A}$ or $\mathrm{B})$ littered in area $\mathrm{A}$,

$\lambda_{i j}=$ number of packs smoked (assumed proportional to the

number littered) by those that reside in area $\mathrm{i}$ and work in area $\mathrm{j}$

$c_{k}=$ share of packs smoked in location $\mathrm{k}(\mathrm{R}=$ residential, $\mathrm{W}=$ work) by a typical worker

$p_{K}=$ share of packs purchased in location $\mathrm{k}(\mathrm{R}=$ residential, $\mathrm{W}=$ work) by a typical worker

${ }^{12}$ Formally, the relative amount of local residents/workers in TAZ i of tax zone $\mathrm{K}$ is computed as:

$$
L R W_{i}^{K}=\frac{\sum_{j=1}^{N}\left[(0.49) W_{i j}^{K}+R_{i j}^{K}\right]}{\sum_{s=1}^{S}\left[\sum_{j=1}^{N}\left[(0.49) W_{i j}^{s}+R_{i j}^{s}\right]\right]} \text { where } W_{i j}^{K}\left(R_{i j}^{K}\right) \text { is the number of workers that work (live) in }
$$

TAZ i of zone K and live (work) in TAZ $\mathrm{j}$ of tax zone K. Data on commuter flows were obtained from Census journey-to-work data. The weight of .49 on employment is the same weight used in selecting sample TAZs and reflects the assumption that residents are likely to spend two-thirds of their time (and do two-thirds of their smoking) in their residence TAZ and one-third in their work TAZ.

${ }^{13}$ In addition to the potential non-representativeness of the litter sample some readers might be concerned that littered packs have accumulated over a long time period and thus do not reflect current incentives to avoid taxes. To investigate this potential issue we re-sampled about ten percent of the TAZs approximately four weeks after the initial sampling. Since the initial sampling removed all littered packs from the routes all packs found in the resample were recent. During the resample we found approximately the same quantities as in the initial sample and conclude that most littered packs are recent. For more detail see Merriman 2008.

${ }^{14}$ Our tabulations are based on scanner data from 3.3 million packs sold during the second quarter of 2002. According to data from the City of Chicago there were almost 30 million Chicago tax stamps sold during that period. Thus, the scanner data may represent only a small fraction of total Chicago cigarette sales. ${ }^{15}$ Lovenheim (2008) estimates that 63.48 percent of Washington, D.C. smokers smuggle. Chiou and Muehlegger (2008) also find that consumers are willing to travel to buy lower priced cigarettes. 
Figure 1

Map of total (Federal+State+Local) cigarette taxes in the Chicago area, 2007

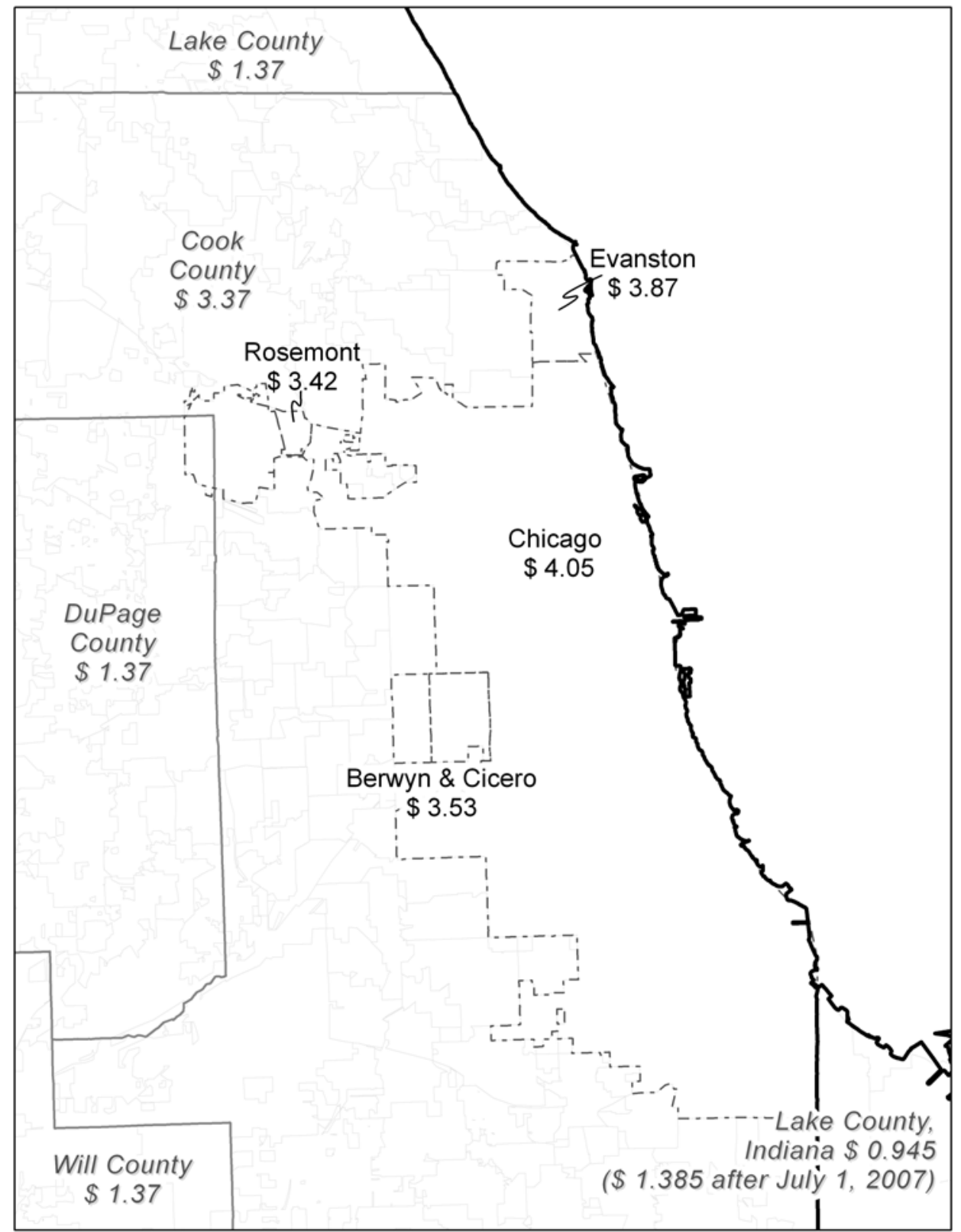

North-south distance is approximately 42 miles

East-west distance is approximately 32 miles.

\begin{tabular}{|c|c|c|c|}
\hline Jurisdiction & Per pack tax July 2002 & $\begin{array}{l}\text { Per pack tax during } \\
\text { sample period: } \\
\text { May-June } 2007\end{array}$ & $\begin{array}{l}\text { Tax increases from July } 2002 \\
\text { through end of sample period }\end{array}$ \\
\hline Federal & $39 \phi$ & $39 \notin$ & none \\
\hline State of Illinois & 584 & $98 \pitchfork$ & to $98 \$$ July 2002 \\
\hline State of Indiana & $55.5 \notin$ & $55.5 \&$ & none (increased to $99.5 \$ 7 / 1 / 07$ ) \\
\hline Cook County & $18 థ$ & $\$ 2.00$ & to $\$ 1$ on $4 / 04$, to $\$ 2$ on $3 / 06$ \\
\hline Other Illinois Counties & $0 \Phi$ & $0 \Phi$ & none \\
\hline City of Chicago & $16 థ$ & $68 \Phi$ & to $48 \$$ on $1 / 05$,to $68 \$$ on $1 / 06$ \\
\hline
\end{tabular}


Figure 2

Images of Chicago, Cook County, Illinois and Indiana Tax Stamps

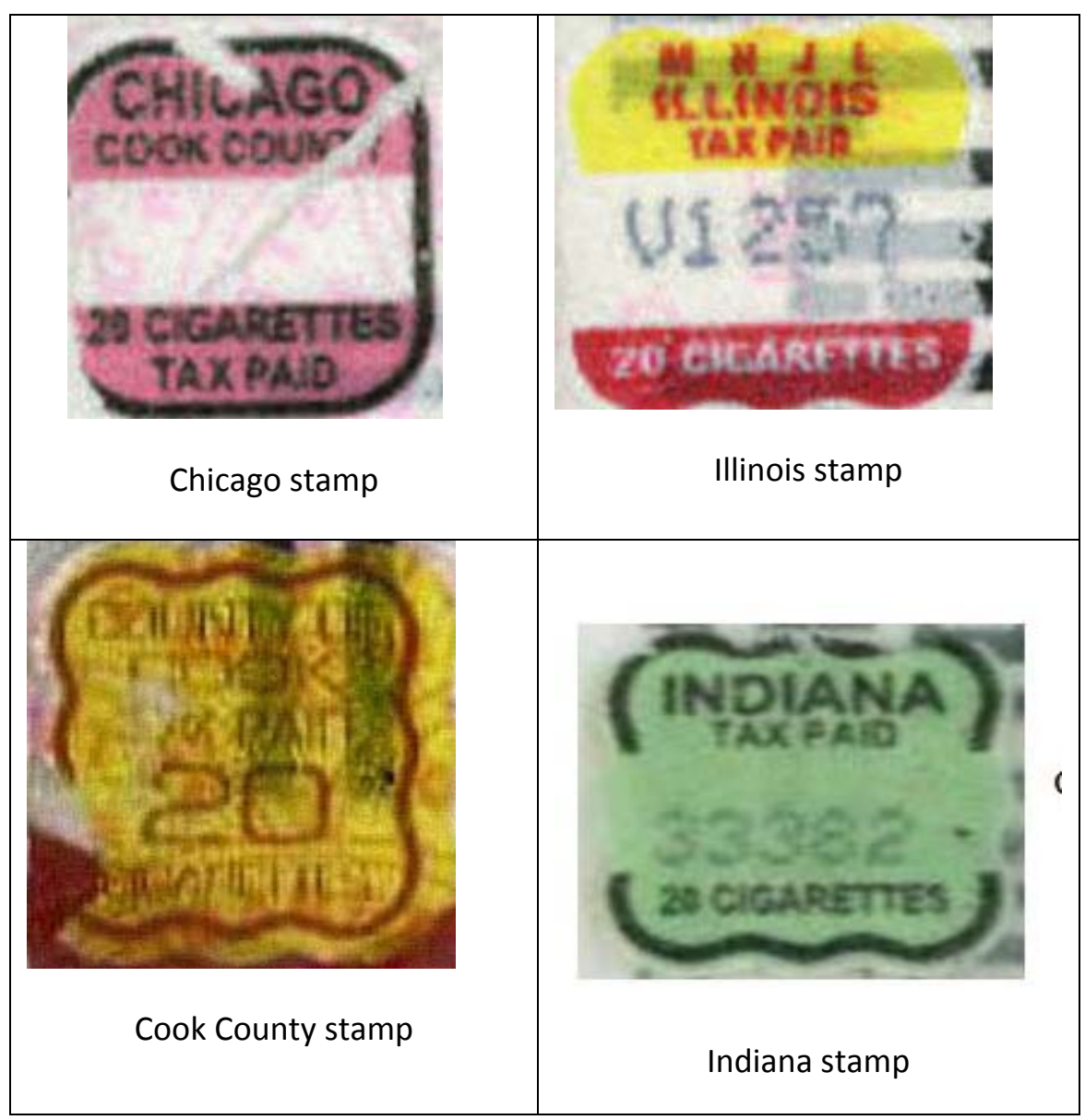


Figure 3. Map of Sample TAZs

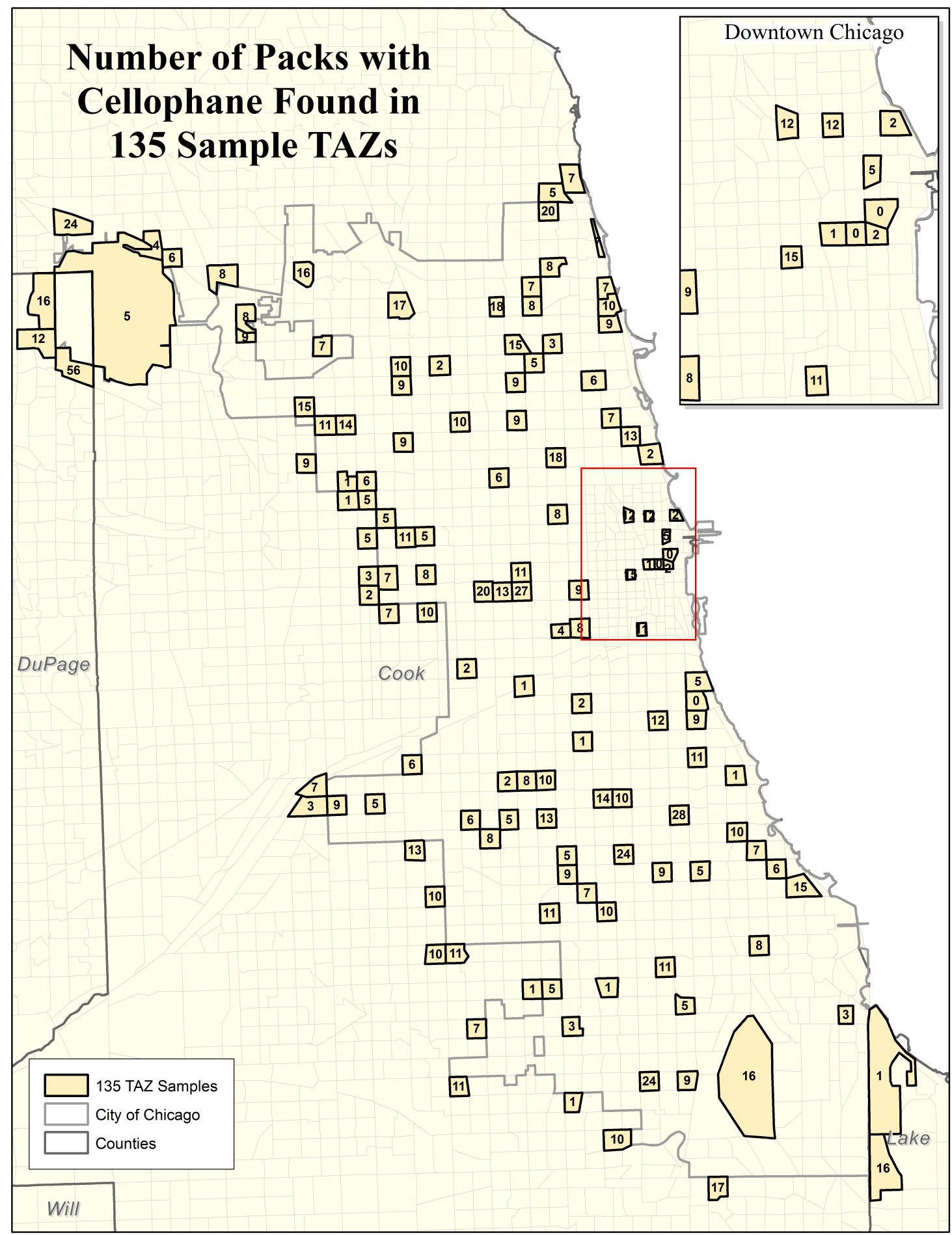




\section{Figure 5 \\ Observed and predicted share \\ by distance (in miles) to Indiana border}

Figure 5A

Chicago stamps

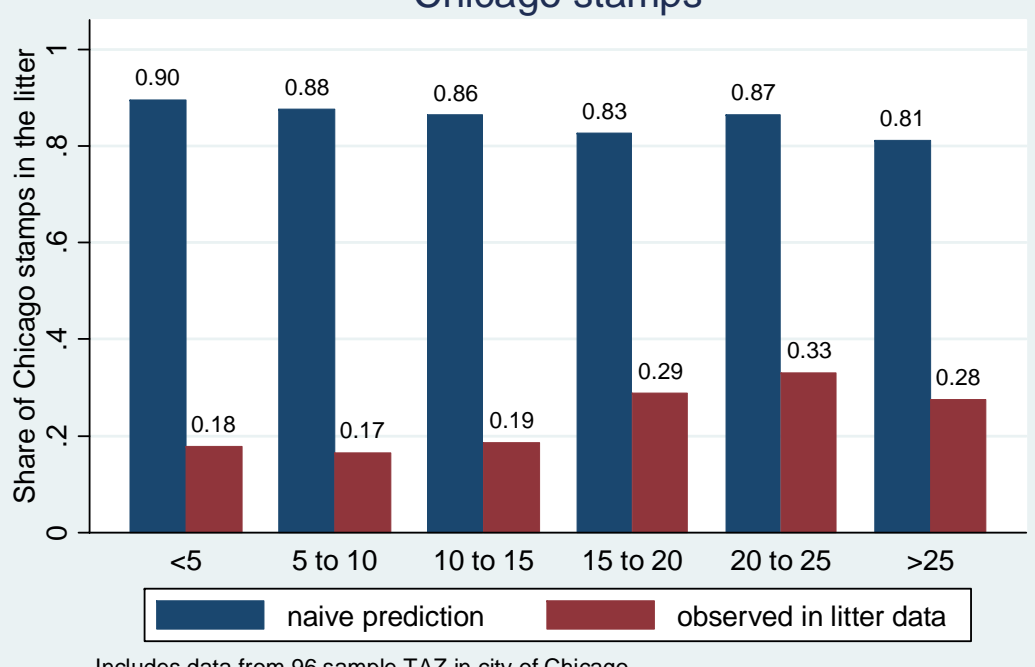

Includes data from 96 sample TAZ in city of Chicago.

Data on three TAZ missing because no littered packs with stamps found.
Figure 5B

Cook stamps

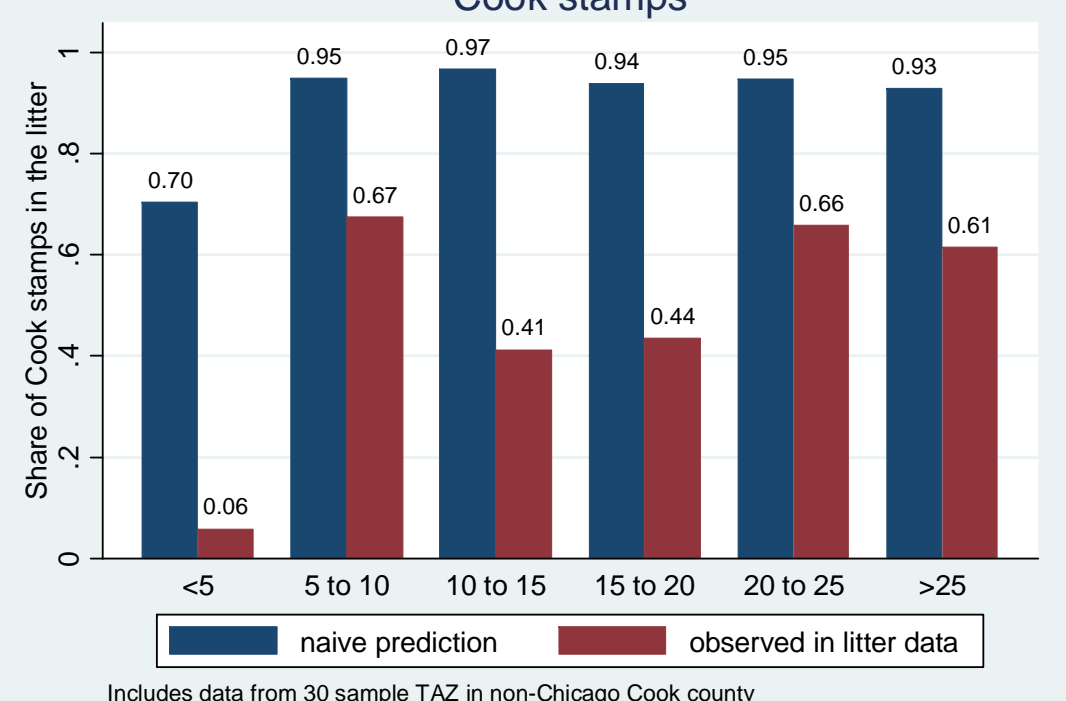

Naive predictions assume only incidental mixing of litter due to commuting. See text. 


\section{Figure 6}

Predicted probability of various tax stamps

as a function of distance to state border*

For 96 TAZs in Chicago
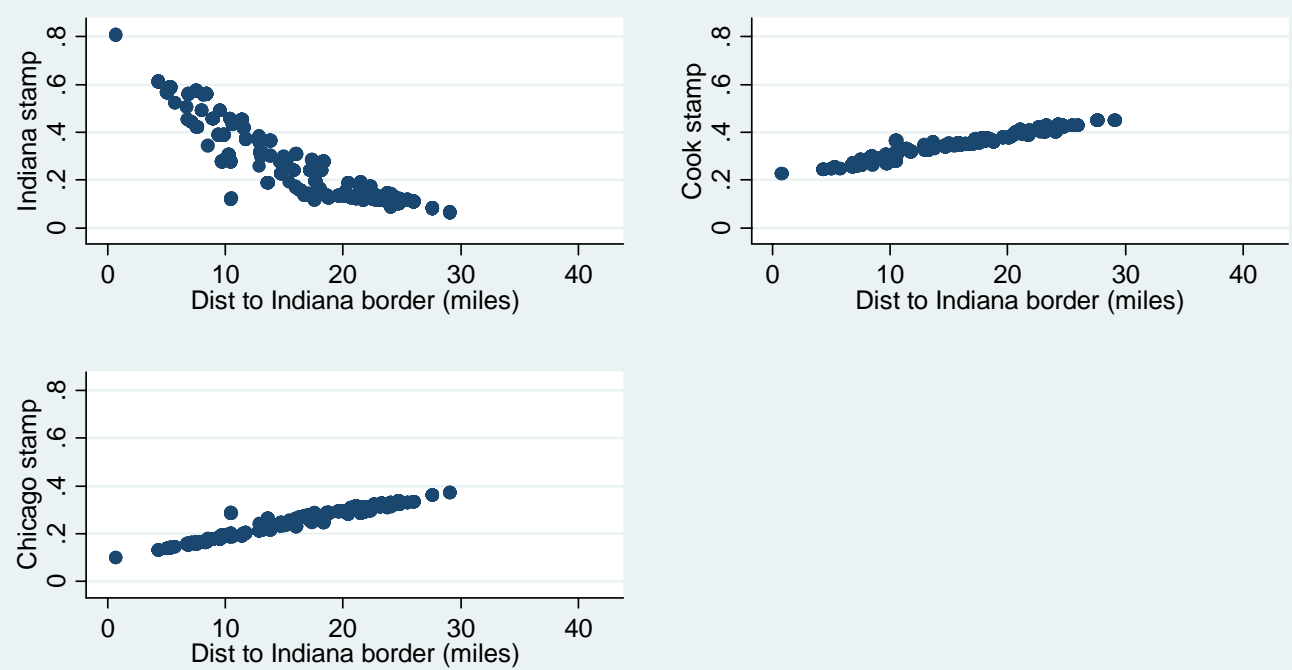

*At observed distance to city, county and state borders and mean of other independent variables

Figure 7

Predicted probability of various tax stamps as a function of distance to state border*

For 30 TAZs in non-Chicago Cook County
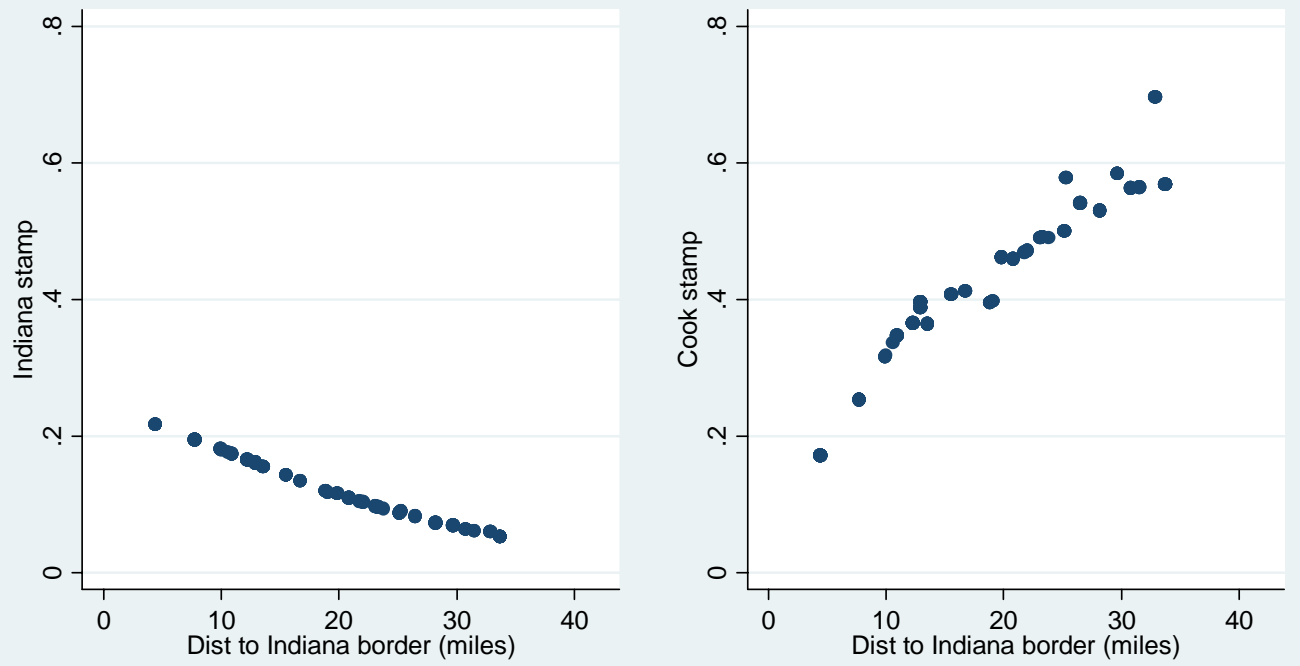

*At observed distance to county and state borders and mean of other independent variables 
Table 1

Summary of TAZ universe and Sample

\begin{tabular}{|c|c|c|}
\hline Location & $\begin{array}{l}\text { Number of } \\
\text { TAZs in } \\
\text { universe }\end{array}$ & $\begin{array}{l}\text { Number of } \\
\text { TAZs in } \\
\text { sample }\end{array}$ \\
\hline In City of Chicago & 930 & 100 \\
\hline $\begin{array}{r}\text { Borders on but not in City } \\
\text { of Chicago }\end{array}$ & 160 & 30 \\
\hline in Cook County & 3 & 3 \\
\hline in DuPage County & 2 & 2 \\
\hline in Indiana & & \\
\hline Total & 1,095 & 135 \\
\hline
\end{tabular}




\begin{tabular}{|c|c|c|c|c|c|c|c|c|c|c|c|}
\hline & \multicolumn{11}{|c|}{ 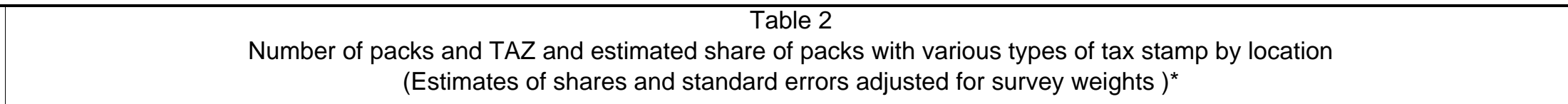 } \\
\hline & & & & A & $\mathrm{B}$ & $\mathrm{C}$ & $\mathrm{D}$ & $\mathrm{E}$ & $\mathrm{F}$ & $G$ & $\mathrm{H}$ \\
\hline place & Location of TAZ & $\begin{array}{l}\text { Number of } \\
\text { packs with } \\
\text { cellophane } \\
\end{array}$ & \begin{tabular}{|l|l} 
Number of \\
TAZ
\end{tabular} & Illinois & Indiana & Other & $\begin{array}{l}\text { No } \\
\text { state }\end{array}$ & $\begin{array}{l}\text { Cook } \\
\text { County }\end{array}$ & $\begin{array}{l}\text { Other } \\
\text { local }\end{array}$ & No local & $\begin{array}{l}\text { Chicago } \\
\text { stamp }\end{array}$ \\
\hline \multirow{2}{*}{1} & & & & $(0.02)$ & (0.02) & (0.01) & (0.01) & (0.02) & $(0.00)$ & $(0.02)$ & $(0.02)$ \\
\hline & $\begin{array}{l}\text { Borders on but not in City of } \\
\text { Chicago }\end{array}$ & & & & & & & & & & \\
\hline \multirow[t]{2}{*}{2} & in Cook county & 218 & 30 & 0.76 & 0.16 & 0.05 & 0.04 & 0.51 & 0.00 & 0.49 & 0.15 \\
\hline & & & & $(0.03)$ & $(0.03)$ & $(0.02)$ & $(0.01)$ & $(0.05)$ & $(0.00)$ & $(0.05)$ & $\overline{(0.03)}$ \\
\hline 3 & in DuPage county & 83 & 3 & 0.83 & 0.01 & 0.09 & 0.07 & 0.19 & 0.00 & 0.81 & 0.10 \\
\hline \multirow{3}{*}{4} & \multicolumn{11}{|c|}{$\begin{array}{l}\text { *Estimates weight each TAZ equally reqardless of the number of packs found. See text for explanation. Row percentages in columns } A, B, C \\
\text { and } D \text { total to } 1 \text { except for rounding. Similarly, row percentages in columns } E, F \text { and } H \text { total to } 1 \text { except for rounding. Column } H \text { is a subset of } \\
\text { column } E \text { since purchase of a Chicago stamp requires payment of Cook County tax. }\end{array}$} \\
\hline & \multicolumn{11}{|c|}{$\begin{array}{l}{ }^{*} \text { In three of } 99 \text { surveyed Chicago TAZs we found no packs with cellophane. We also collected data from the one TAZ that was in the City of } \\
\text { Chicago and in DuPage County. The five packs found in that TAZ (zero with Chicago stamps) are not included in in these tabulations. }\end{array}$} \\
\hline & \multicolumn{11}{|c|}{ Bold typeface indicates estimate is significantly different from Chicago estimate at a 95 percent confidence level. } \\
\hline
\end{tabular}


Table 3

Probit estimates of marginal change in probability of a local stamp from a small change in each independent variable

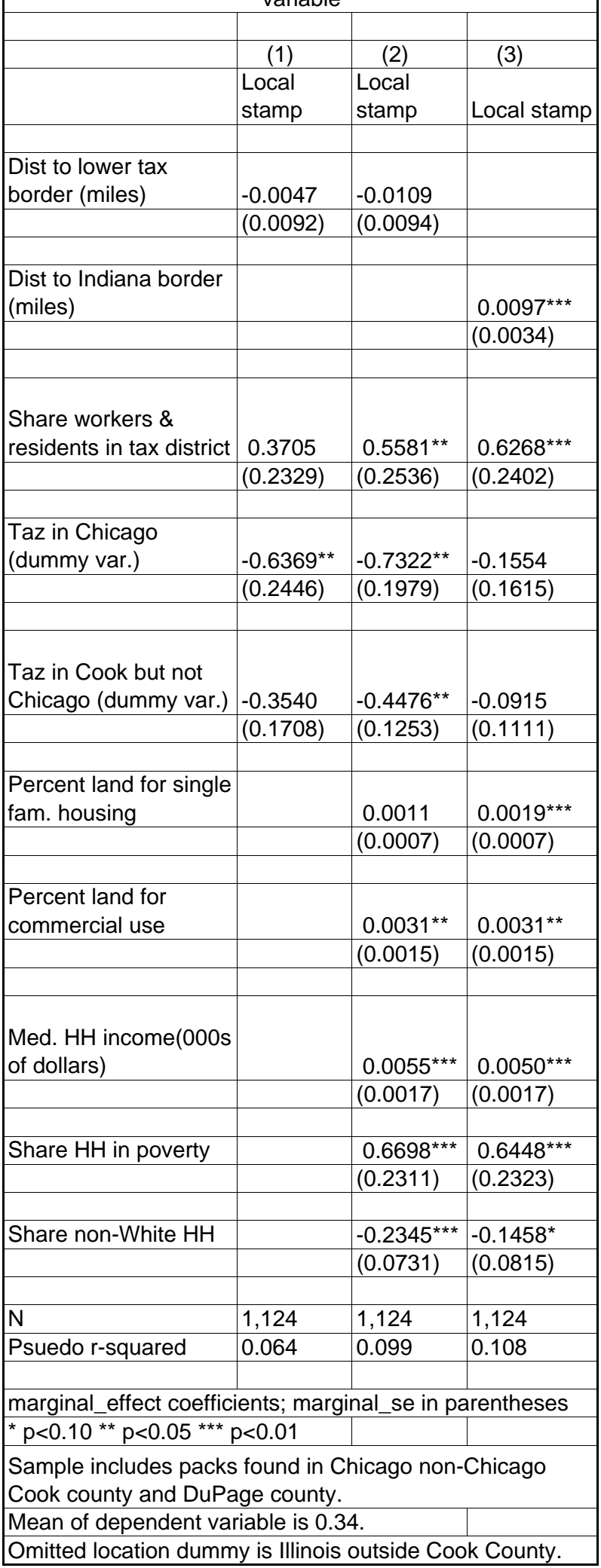




\begin{tabular}{|c|c|c|c|c|c|}
\hline \multicolumn{6}{|c|}{$\begin{array}{c}\text { Table } 4 \\
\text { Probit estimates of marginal change in probability of a local stamp from a small } \\
\text { change in each independent variable }\end{array}$} \\
\hline & & & & & \\
\hline & (1) & $(2)$ & (3) & $(4)$ & $(5)$ \\
\hline & $\begin{array}{l}\text { Indiana } \\
\text { stamp }\end{array}$ & $\begin{array}{l}\text { Cook } \\
\text { stamp }\end{array}$ & $\begin{array}{l}\text { Chicago } \\
\text { stamp }\end{array}$ & $\begin{array}{l}\text { Indiana } \\
\text { stamp }\end{array}$ & $\begin{array}{l}\text { Cook } \\
\text { stamp }\end{array}$ \\
\hline \multirow[t]{2}{*}{$\begin{array}{l}\text { Dist to Chicago border } \\
\text { (miles) }\end{array}$} & $-0.0517^{\text {*** }}$ & 0.0058 & 0.0149 & & \\
\hline & $(0.0191)$ & $(0.0198)$ & $(0.0167)$ & & \\
\hline \multirow[t]{2}{*}{$\begin{array}{l}\text { Dist to Cook county } \\
\text { border (miles) }\end{array}$} & & & & -0.0030 & 0.0426 \\
\hline & & & & $(0.0088)$ & $(0.0269)$ \\
\hline \multirow[t]{2}{*}{$\begin{array}{l}\text { additional dist. to Cook } \\
\text { border }\end{array}$} & $-0.0292^{\star * \star}$ & 0.0111 & 0.0127 & & \\
\hline & $(0.0094)$ & $(0.0096)$ & $(0.0083)$ & & \\
\hline \multirow[t]{2}{*}{$\begin{array}{l}\text { additional dist. to Indiana } \\
\text { border }\end{array}$} & $-0.0259^{* \star *}$ & 0.0078 & $0.0102^{*}$ & -0.0037 & $0.0188^{* *}$ \\
\hline & $(0.0066)$ & $(0.0065)$ & $(0.0053)$ & $(0.0029)$ & $(0.0078)$ \\
\hline \multirow[t]{2}{*}{$\begin{array}{l}\text { Share workers and } \\
\text { residents in Chicago }\end{array}$} & 0.6874 & -0.1580 & -0.0235 & & \\
\hline & $(0.5531)$ & $(0.6699)$ & $(0.6356)$ & & \\
\hline \multirow[t]{2}{*}{$\begin{array}{l}\text { Share local workers and } \\
\text { residents non-Chicago } \\
\text { Cook }\end{array}$} & 0.4859 & -0.1067 & -0.2277 & -0.0032 & -0.1601 \\
\hline & $(0.7212)$ & $(0.8669)$ & $(0.7846)$ & $(0.2372)$ & $(0.4625)$ \\
\hline \multirow[t]{2}{*}{$\begin{array}{l}\text { Share local workers and } \\
\text { residents non-Cook } \\
\text { Illinois }\end{array}$} & 0.3533 & -0.0200 & -1.2392 & 0.8240 ** & $-2.1007^{\star}$ \\
\hline & $(0.9190)$ & $(1.0002)$ & $(0.9231)$ & $(0.4898)$ & $(1.1925)$ \\
\hline \multirow[t]{2}{*}{$\begin{array}{l}\text { Share land for single } \\
\text { family housing }\end{array}$} & $-0.0031^{\star \star}$ & 0.0012 & 0.0014 & 0.0002 & 0.0034 \\
\hline & $(0.0013)$ & $(0.0013)$ & $(0.0010)$ & $(0.0009)$ & $(0.0021)$ \\
\hline \multirow[t]{2}{*}{$\begin{array}{l}\text { Share land for } \\
\text { commercial use }\end{array}$} & $\frac{-0.0025}{(0.0019)}$ & 0.0040** & $0.0028^{\star *}$ & 0.0009 & -0.0031 \\
\hline & $(0.0019)$ & $(0.0017)$ & $(0.0015)$ & $(0.0015)$ & $(0.0038)$ \\
\hline \multirow[t]{2}{*}{$\begin{array}{l}\text { Med. } \mathrm{HH} \text { income(000s of } \\
\text { dollars) }\end{array}$} & $-0.0093^{\star \star \star}$ & $0.0074^{\star \star \star}$ & 0.0021 & $-0.0099^{\star \star \star}$ & $0.0141^{* * *}$ \\
\hline & $(0.0022)$ & $(0.0027)$ & $(0.0021)$ & $(0.0023)$ & $(0.0052)$ \\
\hline \multirow[t]{2}{*}{ Share $\mathrm{HH}$ in poverty } & $-0.8867^{\star \star \star}$ & $0.7194^{\star \star}$ & 0.3791 & $-1.9169^{\star \star \star}$ & $2.8752^{\star \star \star}$ \\
\hline & $(0.2846)$ & $(0.3022)$ & $(0.2618)$ & (0.5189) & $(1.0815)$ \\
\hline \multirow[t]{2}{*}{ Share non-White $\mathrm{HH}$} & 0.1375 & $-0.2126^{\star}$ & $-0.1686^{\star}$ & $0.2779^{\star \star \star}$ & -0.0032 \\
\hline & $(0.1134)$ & $(0.1141)$ & $(0.0938)$ & $(0.1119)$ & $(0.2236)$ \\
\hline $\mathrm{N}$ & 823 & 823 & 823 & 218 & 218 \\
\hline $\begin{array}{l}\text { Mean of dependent } \\
\text { variable }\end{array}$ & 0.29 & 0.36 & 0.25 & 0.16 & 0.51 \\
\hline Psuedo r-squared & 0.17 & 0.0687 & 0.0425 & 0.2415 & 0.142 \\
\hline \multicolumn{6}{|c|}{ marginal_effect coefficients; marginal_se in parentheses } \\
\hline \multicolumn{2}{|c|}{${ }^{\star} p<0.10^{* \star} p<0.05^{* \star *} p<0.01$} & & & & \\
\hline
\end{tabular}




\begin{tabular}{|c|c|c|c|c|c|c|c|c|}
\hline \multicolumn{9}{|c|}{$\begin{array}{c}\text { Table } 5 \\
\text { Comparison of tax avoidance in appropriately disposed of and littered cigarette packs* }\end{array}$} \\
\hline Sample & $\begin{array}{l}\text { Chicago } \\
\text { tax paid }\end{array}$ & \begin{tabular}{|l|} 
Chicago \\
tax not \\
paid
\end{tabular} & \begin{tabular}{|l|} 
Share on \\
which \\
Chicago tax \\
was paid \\
\end{tabular} & $\begin{array}{l}\text { Illinois tax } \\
\text { paid }\end{array}$ & $\begin{array}{l}\text { Illinois tax } \\
\text { not paid }\end{array}$ & $\begin{array}{l}\text { Share on } \\
\text { which } \\
\text { Illinois tax } \\
\text { was paid }\end{array}$ & $\begin{array}{l}\text { Source of } \\
\text { Packs }\end{array}$ & Location \\
\hline 1 & 4 & 3 & 0.57 & 4 & 3 & 0.57 & Nearby Litter & $\begin{array}{l}\text { TAZ } 414513 \text { is a subset of } \\
\text { the receptacle route }\end{array}$ \\
\hline 2 & 6 & 12 & 0.33 & 9 & 9 & 0.50 & Receptacles & 6138 to $7400 \mathrm{~N}$. Sheridan \\
\hline \multirow[t]{2}{*}{3} & 3 & 6 & 0.33 & 6 & 3 & 0.67 & Parallel Litter & 6138 to $7400 \mathrm{~N}$. Sheridan \\
\hline & & & {$[0.14]$} & & & {$[0.38]$} & & \\
\hline 4 & 2 & 5 & 0.29 & 6 & 1 & 0.86 & Nearby Litter & $\begin{array}{l}\text { TAZ } 404501 \text { Southern edge } \\
\text { of litter route is one half mile } \\
\text { from eastern edge of } \\
\text { receptacle route }\end{array}$ \\
\hline 5 & 18 & 13 & 0.58 & 28 & 3 & 0.90 & Receptacles & 1600 to 2018 W. North \\
\hline \multirow[t]{2}{*}{6} & 0 & 0 & & 0 & 0 & & Parallel Litter & 1600 to $2018 \mathrm{~W}$. North \\
\hline & & & {$[0.92]$} & & & {$[0.64]$} & & \\
\hline 7 & 5 & 3 & 0.63 & 6 & 2 & 0.75 & Nearby Litter & $\begin{array}{l}\text { TAZ 294412. Eastern edge } \\
\text { of litter route is one-half } \\
\text { mile from western edge of } \\
\text { receptacle route }\end{array}$ \\
\hline 8 & 19 & 14 & 0.58 & 24 & 9 & 0.73 & Receptacles & 1925 to $2122 \mathrm{~W}$. Division \\
\hline \multirow[t]{2}{*}{9} & 0 & 0 & & 0 & 0 & & Parallel Litter & 1925 to $2122 \mathrm{~W}$. Division \\
\hline & & & {$[0.40]$} & & & {$[0.45]$} & & \\
\hline & & & & & & & & \\
\hline \multicolumn{9}{|c|}{$\begin{array}{l}\text { * Numbers in square brackets [ give the probabilty that there is less tax compliance in the littered data than in the nearby } \\
\text { receptacle data, conditional on our sample. }\end{array}$} \\
\hline \multicolumn{9}{|c|}{$\begin{array}{c}\text { When comparing samples } 2 \text { and } 3 \text { the probabilty that there is less tax compliance in the parallel litter data is } 0.50 \text { for } \\
\text { Chicago taxes, and } 0.20 \text { for Illinois taxes. }\end{array}$} \\
\hline & & & & & & & & \\
\hline
\end{tabular}


Table 6: Comparison of brand shares in scanner data and Chicago tax paid sales litter data* $^{*}$

\begin{tabular}{|l|r|r|}
\hline Brand & $\begin{array}{l}\text { Scanner } \\
\text { data from } \\
\text { Q2, 2002 }\end{array}$ & $\begin{array}{l}\text { Tax paid } \\
\text { littered } \\
\text { sample }\end{array}$ \\
\hline Marlboro & $40 \%$ & $38 \%$ \\
\hline Unidentified Cigarettes & - & $@$ \\
\hline Newport & $12 \%$ & $31 \%$ \\
\hline Camel & $3 \%$ & $6 \%$ \\
\hline Virginia Slims & $7 \%$ & $@$ \\
\hline Kool & $6 \%$ & $11 \%$ \\
\hline Parliament & $4 \%$ & $6 \%$ \\
\hline Benson \& Hedges & $4 \%$ & $@$ \\
\hline Basic & & $1 \%$ \\
\hline Other & $25 \%$ & $8 \%$ \\
\hline Chicago Cig Total & $100.0 \%$ & $100 \%$ \\
\hline
\end{tabular}

* Scanner data based on tabulations of Nielsen data graciously provided by Professor John Tauras of the University of Illinois at Chicago. \# subsumed into "Other" category.

@ subsumed into "Other" catetory 